\title{
Knowledge for a just climate
}

\section{Sheila Jasanoff ${ }^{1}$ (D)}

Received: 2 July 2021 / Accepted: 20 November 2021 /Published online: 23 December 2021 (c) The Author(s), under exclusive licence to Springer Nature B.V. 2021

Keywords Climate change $\cdot$ Science and technology studies $\cdot$ Co-production $\cdot$ Geoengineering $\cdot$ Environmental justice

"America needs to be on the cutting edge of climate research. More knowledge is always better."- Rep. John Curtis (R-UT) (New York Times, 3/25/21)

\section{Essay}

Climate science has garnered its share of prophets and priestesses in the twenty-first century, sometimes from unexpected quarters: school children, for example. When sixteen-year-old Greta Thunberg sailed across the Atlantic and addressed the US House of Representatives in September 2019, she clothed her mission in the authority of science. Instead of written testimony, she offered an October 2018 report from the Intergovernmental Panel on Climate Change (IPCC) calling for a radical transformation of the world economy. Sounding the refrain that she put front and center throughout her US visit, Thunberg said: "I am submitting this report as my testimony because I don't want you to listen to me, I want you to listen to the scientists. I want you to unite behind science. And then I want you to take real action."

Thunberg's climate crusade has inspired the young. All over Europe and North America youth have mobilized on a scale not seen since the political movements of the 1960s. Only they are much younger this time, and their rallying cry is not justice, peace, or morality in the first instance, but science. Extinction Rebellion (XR), the group that formed in October 2018 to bring dramatic non-violent protest into the heart of London, is on the same page as Thunberg's movement, Fridays for Future, when it comes to knowledge of climate change and its impacts. XR's website announces: "The science is clear: It is understood that we are facing an unprecedented global emergency. We are in a life or death situation of our own making. We must act now."

These and many other high-profile climate-related demonstrations of the last decade in the global North force us to rethink what the word "usable" means in relation to climate

This article is part of the topical collection "Critical and historical perspectives on usable climate science," edited by Deborah R. Coen and Adam H. Sobel.

Sheila Jasanoff

sheila_jasanoff@harvard.edu

1 Harvard Kennedy School, 79 JFK Street, Cambridge, MA 02138, USA 
science. It is implicit in the work drawn together under this rubric that enrolling the power of climate science is essential for planetary health, and even that more intensive use of science is a prerequisite for achieving global social justice. There is, too, a suggestion that science needs translation to be made more "usable" for purposes of policy action. All these presumptions bear questioning in the light of the ambiguous history of climate decisionmaking over the past half-century. In particular, we need to query the term "climate science" to form a clearer picture of how it advances (or does not) the coupling of knowledge and justice.

Climate science refers, in the first instance, to a steadily growing body of knowledge, ably assessed and compiled in the IPCC's cumulative reports, that has established undeniable connections between human activity and climate change. At once historical and predictive, the IPCC reports have underscored the suddenness and severity of the changes occurring in the Earth's physical and biological systems: among them, sea level rise, extreme weather events, biodiversity loss, and mass extinctions. This knowledge is already sufficiently "usable" in the minds of many actors around the world, as exemplified in the modern-day children's crusades led by Thunberg and the plaintiffs in lawsuits such as Juliana $v$. United States. For all the hundreds of thousands who have taken to the streets worldwide to demand immediate climate action, science has already spoken clearly enough: there is no need to make it yet more usable.

Global mobilization in response to climate science, then, is not a mirage or a vain hope. It is already in progress. Indeed, the most pronounced manifestations, whether through direct action such as XR's or through official policy at levels of government from the international to the municipal, are in the regions that have historically contributed most to the problem through their greenhouse gas emissions: that is, Europe and North America. These are also the regions where one sees the bulk of leading-edge climate science, pointing to intimate connections between knowledge generation and political awakening. At the September 2019 UN General Assembly meeting, for example, former New York Mayor Michael Bloomberg, reappointed UN Special Envoy on Climate Change in February 2021, called attention to the increasing role of non-state actors in leading climate action. He noted that, even in the USA, a country often seen as erratic or lagging on climate change, policy activism cuts across scales and sectors: "A growing number of U.S. cities, and states, and businesses have committed to reaching net-zero emissions. These states would by themselves form the world's fourth-largest economy."

What if we turn the question of use around, however, and ask not how science can be better put to use, but whether it is the right science- - knowledge that not only tells us how and where climate change is occurring, but also what we should be doing to reduce its most inequitable impacts? What sorts of climate research are needed to advance the cause of justice, and how can one ensure that such research, if done, will be heeded-or used-by policymakers? One widely accepted answer is to say that the causes of climate change are now so thoroughly understood that scientists should focus more of their energies on impacts. This, at first glance, seems a reasonable proposition. Justice, after all, requires us to pinpoint with greater accuracy how the burdens of an unstable climate might fall on diverse populations, with what discrepant welfare effects. Impact analysis speaks to these demands.

A relatively new branch of climate research, attribution science, serves a similar purpose. This line of work allows scientists to assess the likelihood of a connection between climate change and "natural" disasters such as hurricanes, wildfires or extreme flooding. In principle, better attribution could serve as a first step toward allocating responsibility, especially if impacts fall disproportionately on marginal populations. Yet, attribution science is only a starting point. On its own, it says little about 
who will be affected, how much, and with what consequences for social order. The social sciences of vulnerability and resilience might enable us to craft more equitable policies than more refined natural science studies of different aspects of climate phenomena. A turn toward questions of distribution and vulnerability would be consistent with the position I advocated in my 2003 article on "technologies of humility." But this too may not get to the heart of the question: are the sciences we are generating useful for a just world?

\section{The limits of technological solutions}

On the whole, climate research today is not suffering from a lack of interest or resources. Many leading research universities have heeded the call for usable climate science and initiated research programs that aim to pull together cross-disciplinary strengths across the natural and social sciences. To date, however, efforts in the global North remain decidedly tilted toward finding engineering solutions to climate problems. An ambitious example is Cambridge Zero, an initiative by the University of Cambridge (UK), announced in late 2019, not only to develop greener technologies but to "harness the full power of the University's research and policy expertise, developing solutions that work for our lives, our society and our economy." Yet, a glance at the contributing centers shows that the impulse to know has not engaged all of the university's intellectual resources. It remains more concentrated on technical problems and material solutions than on the normative questions posed by climate change. There was to start with little explicit role for history, philosophy, or science and technology studies (STS), among other humanistic fields. The social science emphasis appeared to be dominated by economics, a branch of knowledge associated more with efficiency than with concern for the social determinants of inequality and injustice.

To be sure, the very urgency of climate change means that short-term technological fixes are now demanding more attention and resources (e.g., geoengineering in its varied forms). A 2021 report of the US National Academies of Science, Engineering and Medicine, innocuously titled Reflecting Sunlight, called for \$100 million to be spent on studying strategies such as marine cloud brightening, stratospheric aerosol injection, and cirrus cloud modification. Geared toward producing specific results, such research is utilitarian by definition and there is little reason to worry that breakthroughs, if any, will not be taken up by governments anxious to protect their polities against grave and immediate harms. The greater concern is that the very appeal of such promissory research will make for less critical review and uptake, with marginalized populations once again least likely to be able to voice their objections in time. Precisely, such reasoning led to wide mobilization among scientists and indigenous groups who successfully lobbied the Swedish Space Agency to cancel SCoPEx (Stratospheric Controlled Perturbation Experiment). This project originating at Harvard University would have launched a test balloon to study small-scale air perturbation over a number of hours to observe processes that would be implicated if chemical aerosols were injected into the stratosphere.

Sweden's about-face on SCoPEx is a dramatic example of a more general disconnect between science and engineering research on the one hand and research on the normative implications of such research on the other. Clearly, technological enthusiasm in 
this case went ahead of securing the assent of potentially affected groups such as the local Sami population.

\section{Co-production: reframing the questions}

In the wake of the SCoPEx cancellation, it is all the more important to ask two persistent questions that relate to climate research for social justice:

- What is it about the production of climate science as conventionally understood that inhibits justice, and how might knowledge-making be made more compatible with society's demand for just climate policies? Is more science, as Representative John Curtis of Utah stated concerning the Reflecting Sunlight report, always better?

- Why, in the face of mounting scientific knowledge of climate change, and its causes and consequences, are substantial segments of developed nation publics still not persuaded of the need for urgent action? Put more pointedly, why when Northern school children were striking weekly could President Donald Trump of the USA pull out of the world's most significant climate accord without substantial political cost and come uncomfortably close to reelection?

For some answers, we can turn to accounts of climate science and its reception from science and technology studies and associated fields of interpretive policy analysis.

With respect to the first question, many have argued that knowledge-making on climate change could and should be made more participatory and inclusive. The track record of the IPCC shows that, from its fourth report, this authoritative body began recognizing the importance of pulling indigenous knowledge into its assessments of impacts, although these efforts perhaps predictably were judged inadequate by groups that had felt excluded from prior assessments. Numerous organizations, such as Future Earth, have taken it upon themselves to extend the IPCC's baby steps through more ambitious efforts at what is sometimes called the co-production of knowledge. Future Earth proposes four principles to improve the likely efficacy of such processes: they should be context-based, pluralistic, goal-oriented, and interactive.

While pluralism and interaction are surely worthy principles when developing knowledge to serve the interests of all humanity, this understanding of co-production, as goaloriented epistemic negotiation, does not address a fundamental quandary that STS scholars have identified with regard to science in general and climate science in particular. That quandary centers on a very different understanding of what knowledge production entails as a social matter: not simply the construction of agreed-upon facts with respect to preordained goals, but a more complex, multivalent exercise, in which the purposes of knowledge-making are up for grabs at the same time as more bounded debates on methods or the weight of the evidence for and against particular positions. Co-production as understood by STS scholars problematizes the goals of fact-finding along with the means of making facts. That dual questioning defines a fluid space of inquiry that cannot be made tractable through simple "pluralism" (who, after all, belongs at the table when we don't know what the table is?) or "interaction" (to what ends, if we do not agree which ends are desirable?).

The starting point for thinking about co-production in STS is the recognition that building new "states of knowledge" (Jasanoff 2004) about the world is not normatively innocent but entails inescapable, concurrent judgments about how we should direct and govern 
our lives as we go about generating new knowledge. Climate science, in particular, radically disrupts people's understanding of what gives their lives meaning, shape, and worth. By redefining ourselves as a planetary collective that has wrought potentially irreversible changes in all of Earth's functioning systems, climate science has dislocated how we previously understood and positioned ourselves in terms of place, time, economics, and politics (Jasanoff 2010). These disruptions necessarily have a bearing on people's sense of justice, whether because of increased vulnerability to climate effects, ruptures in existing lifestyles, or a demand for nearterm sacrifices to benefit distant communities not of one's own kind. Future generations are a prime example. I met a villager in India once, in the late twentieth century, who asked how he could save trees for people not yet born when he could not find ways to feed his own children and grandchildren. What answer could climate science give him, and how might any of the IPCC's vast reserves of knowledge be translated into forms that such a person might find useful?

Those at the receiving end of climate science are keenly aware that there is an element of force involved in imposing new knowledge upon their world. If scientific assertions compel action, attention, and subservience, then science is acting like any other instrument of power that a state or other governing body commands. At the limit, the calculus of climate science can erase the meaning and significance of the lives of those actually living them, in embodied form. As a Brazilian interlocutor poignantly told the Brundtland Commission:

You talk very little about life, you talk too much about survival. It is very important to remember that when the possibilities for life are over, the possibilities for survival start. And there are peoples here in Brazil, especially in the Amazon region, who still live, and these people that still live don't want to reach down to the level of survival (World Commission on Environment and Development 1987).

A crude term like "climate denial" takes little or no account of the sociopolitical and economic reasons why human survival in distant climate futures, projected on the basis of strategic erasures and aggregations, might be a lot less relevant to such a speaker than living in the here and now. Yet, to date, more research and debate have focused on the psychological orientations of so-called deniers, and on strategic moves by political actors (Skocpol 2010) in response to a black-boxed "mainstream science," than on the ways that social constructions of collective knowledge, or ignorance, systematically occlude or deny some types of claims to justice (Jasanoff 2017). Who, after all, calculates the value of living as opposed to survival?

\section{Hegemonic knowledge, hidden norms}

Climate science, as generated by the IPCC, has itself been perceived as an instrument of injustice, even hegemony, in parts of the world that did not originate its dominant forms of model-based knowledge. Evidence of such a reaction can be found in Martin Mahony's case study of the Himalayan glacier controversy. The conflict originated in a dispute between Indian glaciologists and the IPCC about what proved to be an error in the latter's $4^{\text {th }}$ Assessment Report, claiming that Himalayan glaciers were rapidly receding and would disappear by 2035. One consequence of the dispute, Mahony found, was to kindle a sense in India of the close relationship between epistemic and political sovereignty, spurring the creation of a new national expert body, the Indian Network for Climate Change Assessment. Indeed, then environment minister Jairam Ramesh was quoted making the 
co-productionist point that climate science is politics by other means (Mahony 2014). One could see this as a moment of cosmopolitan knowledge-making, in which the Indian state recognized that its autonomy demanded, in effect, that it had to be the author of its own climate knowledge. Letting outsiders control how to know local terrains and conditions, such as glaciers and monsoons, was a recipe for ceding some control over the nation's future.

A still earlier controversy, between India's then-young Center for Science and Environment (CSE) and the World Resources Institute illuminated the profound ways in which choices of what and how to measure in relation to climate change already contain, in an STS co-productionist sense (Jasanoff 2004), the seeds of future injustice. CSE's critique was not simply about wanting to be admitted into the rich country climate club, in order to contribute another perspective on the science. Rather, it was about rewriting the very terms in which one should interrogate the phenomenon of climate change.

In their pathbreaking 1991 report, CSE co-authors Anil Agarwal and Sunita Narain urged that carbon emissions should not be measured as a single "natural kind" (Hacking 1991) but should rather be divided into different categories corresponding to their sources in social life. Such a move, they argued, would justly differentiate the "luxury emissions" of the rich from the "subsistence emissions" of the poor. The IPCC ignored this plea, not through malice, but because of its culturally conditioned inability to see greenhouse gases as anything but "natural" and its oft-stated commitment to separating science from policy-in a textbook example of what STS calls boundary work. Numbers, on this view, must be objective and untouched by politics to be just, and this requires that they be seen to stand apart from politics. The result, as we have seen, was that the IPCC over several decades produced quantitative science that was eminently usable in the eyes of knowledgeconsumers and climate activists in Northern nations. As already stated, it energized First World youth to demand climate policy that takes their futures explicitly into account. But was the IPCC's vision of an apolitical science also seen as science for justice to serve the world? Many said no, and many still do-whether through denial of the science, as among America's fossil-fuel advocates, or through calls for decoupling the obligation to control emissions from national emissions levels under the principle of common but differentiated responsibility.

All this suggests that, on the second question above, the inquiry has to expand from the concept of useful or usable science to asking why people believe particular expert claims are worth acting on. That, in turn, calls for deeper understanding of the construction of trust and credibility in modern societies, including trust in expertise. Here, too, STS offers some analytic resources for understanding what makes the esoteric knowledge of bench science persuasive to wider communities. The integrity of scientists and their historical record in problem-solving are surely part of the explanation, but they are not alone enough. A dramatic illustration in the Covid-19 era is the phenomenon of vaccine hesitancy, a widespread reluctance to be vaccinated against the coronavirus, despite repeated expert assurances that this treatment is safe, highly effective, and the most important defense we have against yet more lethal variants emerging. Such examples suggest that, in cases of public doubt, more is in play than the reputation of mainstream scientists or the strength of their consensus.

In promoting usable climate science, US research has tended to be somewhat parochial in its orientation. As one of the lead players, if not the world hegemon, in climate modeling and integrated assessment, US climate research perhaps understandably places greatest weight to the production end of the knowledge/belief spectrum. US analysts of climate skepticism have tacitly tended to buy into a linear notion of the impact of knowledge on 
action. In this model, more and better knowledge is seen as a driver of more and better public buy-in and policy response. This is a pervasive belief. Even a Republican Congressman from one of America's "red states," John Curtis of Utah, knows that "more knowledge is always better." The rise of young activists like Thunberg and the Juliana plaintiffs, who seem so driven by science, has reanimated that article of faith, especially within the often beleaguered American climate science community. But the links between the strength of knowledge and the firmness of public confidence in that knowledge are far from straightforward.

Comparative studies of the use of science in policy provide additional insights. It has long been observed that societies do not respond in the same ways to the same scientific findings. Moreover, in highly structured societies such as the modern nation state, we can discern patterned ways of public knowing that I have termed civic epistemologies. These divergent knowledge ways are constitutive of political cultures and account for sometimes radical discrepancies in the reception and uptake of the same scientific claims and findings by different national publics. US citizens have been demonstrably more dubious about the causes and consequences of climate change (and more recently about the seriousness of Covid-19), and more receptive to alternative theories, than their counterparts in other advanced industrial nations. In this context, merely doing more or different science may not lead to usable results, any more than maintaining a tally of Trump's lies persuaded members of his most ardently committed constituencies to abandon him. As of 2021, the USA remains a house divided in its understanding of what science is important for policy, and hence also in its evaluation of the integrity, independence, and public-mindedness of the individuals and institutions producing that science.

\section{Conclusion}

Three points can be made in conclusion:

First, science generated without regard to questions about whose purposes it serves is not likely to persuade those who feel that their needs and interests were not heeded by the knowledge-makers. If the goal of research is felt to be politicized from the start, then skeptics will feel no compulsion to use the resultant knowledge to reorder the foundations of their social, political, and economic lives. As is well-known from context of patient noncompliance, the more radical the prescriptions for reordering lives, the less likely it is that people will unquestioningly follow the advice of science.

Second, the science of how the climate works will not move societies to action in and of itself; one needs symmetrical attention to why societies trust, or do not trust, the makers and interpreters of that science. In short, the quantitative, aggregative approaches that have characterized mainstream climate research need to be supplemented by critical, interpretive work that traces the deep structures connecting people's sense of justice with the ways in which the sciences have represented their world.

And, third, knowing the climate system inside out in scientific terms will never be sufficient to illuminate what ideas of global social justice are abroad in the world, what histories gave rise to them, and how they link to people's hopes and fears about the long-term future of their species and their Earth. 
Data availability Not applicable

Materials availability Not applicable

Code availability Not applicable

\section{Declarations}

Conflict of interest The author declares no competing interests.

\section{References}

Jasanoff Sheila (ed) (2004) States of Knowledge: The Co-production of Science and Social Order. Routledge, London

Sheila Jasanoff (2010) A new climate for society. Theory Cult Soc 27(2-3): 233-253

World Commission on Environment and Development (1987) Our Common Future. Oxford University Press, Oxford, p 40

Theda Skocpol (2010) "Naming the Problem,” January 2013; see also Naomi Oreskes and Erik M Conway, Merchants of Doubt: How a Handful of Scientists Obscured the Truth on Issues from Tobacco Smoke to Global Warming (New York: Bloomsbury Press)

Sheila Jasanoff (2017) Virtual, visible, and actionable: data assemblages and the sightlines of justice. Big Data Soc 4(2) https://doi.org/10.1177/2053951717724477

Martin Mahony (2014) The predictive state: science, territory and the future of the Indian climate. Social Stud Sci 44(1):109-133, at p. 119

Jasanoff (2004) States of Knowledge

Ian Hacking (1991) A Tradition of Natural Kinds. Philos Stud 61(1/2):109-126

Publisher's note Springer Nature remains neutral with regard to jurisdictional claims in published maps and institutional affiliations. 